\title{
Efficiency and effectiveness evaluation of project- oriented activities in the Ministry of industry and trade Russia
}

\author{
Vasili Osmakov \\ Deputy Minister \\ Ministry of Industry and Trade \\ Russia \\ Moscow, Russia
}

\author{
Vladimir Pastukhov \\ General Manager \\ Russian Technology Agency \\ Moscow, Russia \\ Grigory Tsipes \\ Consulting \& Development Department \\ IBS \\ Moscow, Russia \\ gtsipes@ibs.ru
}

\author{
Aleksandr Tovb \\ President \\ SOVNET \\ Moscow, Russia \\ atovb@sovnet.ru
}

\begin{abstract}
The Ministry's area of responsibility annually includes more than a thousand industrial projects of various sizes that receive are funded by the state. The Ministry's approach to managing these projects is to balance the distribution of responsibilities among key stakeholders. This means that the operational management of projects is delegated to the level of contractors, and the functions of the strategic and tactical level are centralized in the federal or regional executive authority. Such an approach requires a high level of project management culture, based on three main components - customers competence, contractors competence and corporate management system maturity. The Ministry considers its objective in the continuous development of all three components. The special assessment model was developed for this purpose specifically of the industrial sector.
\end{abstract}

Keywords-industrial project, system engineering, project governance, project management, voluntary certification, organisational competence.

\section{INTRODUCTION}

The Ministry's area of responsibility includes more than a thousand industrial projects of various sizes that receive state funding annually. The Ministry's approach to managing these projects is to balance the distribution of responsibilities among key stakeholders. This means that the operational management of projects is delegated to the level of contractors, and the functions of the strategic and tactical level are centralized in the federal or regional executive authority [1].

Such an approach requires a high level of project management culture, which can be defined by a simple "formula":

$$
\begin{gathered}
\text { Effective and efficient projects }=\text { Competent } \\
\text { customer }+ \text { Competent contractor }+ \text { Mature } \\
\text { management system }
\end{gathered}
$$

The Ministry considers its objective in the continuous development of all three components. The special assessment model was developed for this purpose specifically of the industrial sector.

The competency assessment model for the executive authorities, as an investor of projects, was developed based on the IPMA Delta@ model. However, it was adapted to the specifics of the project activities of the Ministry in terms of the evaluation criteria and the assessment procedure. In particular, the balance of attention in assessment is shifted from project management to project governance, which corresponds to the role of the Ministry in industrial projects.

The assessment model of project competence of industrial enterprises includes three components organization of project activities, project management and system engineering. The latter component is especially important for industrial projects since it allows to evaluate management technologies that are used to develop and produce complex products and systems. The methodological base of this model combines the ideas of IPMA PEB, IPMA OCB and CMMI

The model of competence or maturity of the project management system is focused on the peculiarities of the current period - the active creation of regional state structures for managing projects (including industry) and the relatively low level of project culture of officials. An assessment is conducted to harmonize federal and regional practices, identifying and replicating the successful experience. The basis for this model was the methodological recommendations of the Russian Federal Project Management Office and the Ministry PMO, representing, respectively, the specifics of project management in the executive branch and industryspecific.

The paper also presents examples of practice applying these models and some conclusions based on the results of the assessments. 


\section{PRoJect MANAGEMENT COMPETENCY MODEL OF THE EXECUTIVE AUTHORITY}

\section{A. Object of Assessment}

A significant part of Ministry activities is performed in a project form and includes two main groups - internal and external projects. Internal projects are focused on main areas of the Ministry's responsibility, for example, development of strategies and regulations, organizing of exhibitions and fairs. They may also be launched for improving the efficiency of the Ministry's activities, for example, development of information systems, optimization of internal processes etc. Group of external projects includes industrial and R\&D projects funded by the Ministry in the interests of organisations from different industries. These projects could be initiated by a company, an enterprise or the Ministry itself, but in all cases, the beneficiary of such projects are companies and enterprises. The Ministry governs and manages more than a thousand projects implemented simultaneously. These projects are very different in purpose, scale, complexity, resources, as well as the role of various officials - experts, performers, project managers, project sponsors etc.

\section{B. Evaluation tools and techniques}

The IPMA Delta ${ }^{\circledR}$ model was used for the study as a methodological basis [2]. It was adapted to the specifics of the project-oriented activities of the Ministry in terms of setting the criteria and procedures for carrying out the analysis [3]. The evaluation model includes 28 criteria that have comprised four groups project governance, organization of project management processes, the competence of project personnel and the interaction of projects with the external environment. The evaluation of the criteria is carried out using a questionnaire. The questions are formulated in terms of "positive judgments", and respondents should express their attitude to these judgments using Likert scale - from strongly disagree to strongly agree. Instructions and guidelines for respondents have been developed with examples of possible additional information on a request for each criterion. In this way, the respondents know which additional materials (regulations, manuals and other normative and methodological documents) could be asked to provide to the assessors and which additional questions respondent could be asked during the interview. The estimate is calculated arithmetically for all respondents individually, by criteria groups and by departments of the Ministry. The evaluation process includes two phases. First, collection, analysis and verification of input data and second, development of recommendations.

\section{Case study}

Approbation of the model was performed for one of the Ministry's departments most actively involved in the project-oriented activity (hereinafter referred to as the Department). The project-oriented activity scope involves all employees of the Department In this or that role, so all groups of employees were involved in the study. In general, the survey involves more than $20 \%$ of the Department staff, including top and middle managers, vastly engaged in project-oriented activities. Respondents were selected to fully cover the project-oriented activity of the Department. One of the important results of the study was a more profound understanding of the essence and features of the project activity by the Department's staff. It's illustrated in evaluating the criteria given by the staff in the questionnaires before and after the interview:

- radical (more than threefold) reduction in the number of evaluations "neither yes nor no";

- the "shift of estimates to the right" has significantly decreased, that is, the number of overly optimistic estimates has been reduced.

The research also showed almost identical profiles of estimates made by the Department's topmanagement and line personnel. It led to a conclusion about the uniformity of the opinions of the entire Department's staff (Fig. 1). Taking into account this fact, the conclusions and recommendations based on the results of the research were made. The opinions of all respondents were taken into account without dividing them into segments.

a) Top-management of the Department

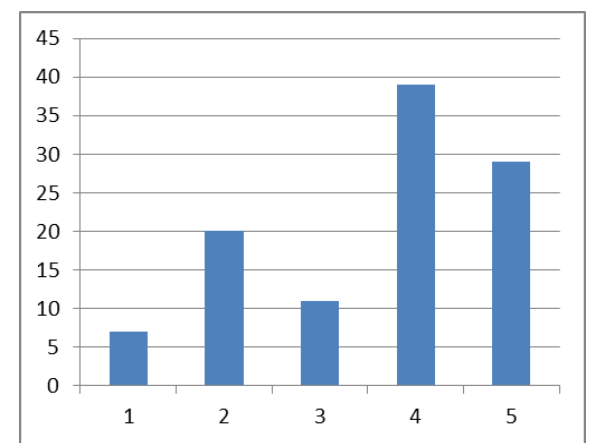

b) Line personnel of the Department

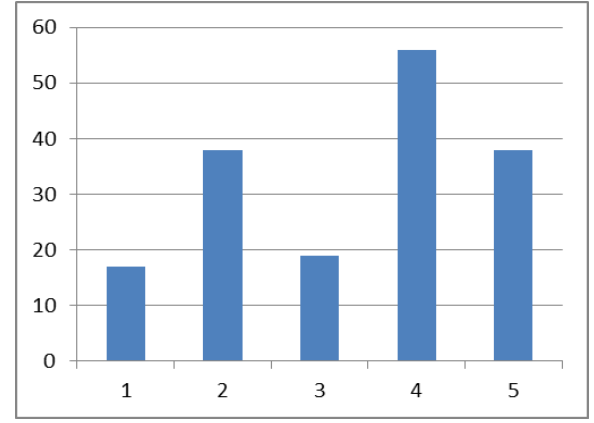

Legend:

1 - answers «Strongly disagree»

2 - answers «Disagree»

3 - answers «Neither yes nor no»

4 - answers «Agree»

5 - answers «Strongly agree»

Fig. 1. Uniformity of opinions by segments [3] 
Comparative analysis of the research results by groups of criteria showed that the most underdeveloped area is the competence of the project personnel (Fig. 2). This conclusion, drawn from the results of the questionnaire, is also confirmed by a large number of evaluations "neither yes nor no", exhibited at the initial completion of the questionnaires, which indicates a weak methodical background in the field of project management of many respondents. It should be noted that the results of the interviews also confirmed this conclusion.

At the same time, according to the assessors, high estimates on other criteria groups cannot be fully justified. In many cases, the respondents submitted estimates without having a basis for comparison and not knowing good practices, which is due to the small personal experience of the project activity.

In the opinion of the assessors, this led to an overestimation on a number of criteria. Taking these considerations into account, a reduction factor of 0.8 ("Optimism Index") was applied to clarify the final integrated estimate. As a result, the overall (average) score for the Department was 2.4 points, which corresponds to the second class of competence in the IPMA Delta ${ }^{\circledR}$ Model ("Defined" class).

\section{ASSESSMENT MODEL OF PROJECT COMPETENCE OF INDUSTRIAL ENTERPRISES}

\section{A. Vision and approach}

The Ministry considers the Voluntary Certification System (VCS) of industrial enterprises competence in project management $(\mathrm{PM})$ to be one of the most effective tools for the development of project management culture. Voluntary certification is considering not as much as a tool of confirming the achieved level of competence, but primarily as a way to draw the enterprise into a spiral of development and to support them along the way.

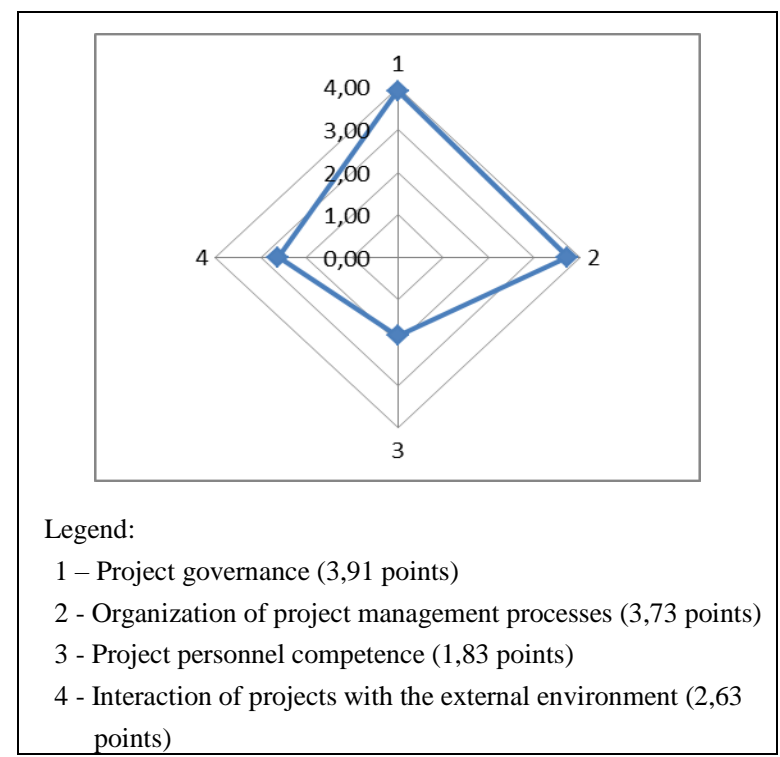

Fig. 2. Analysis of estimates by groups of criteria [3]
The VCS was developed due to two important reasons. First, the direct transfer of well-known models from the field of project management into the sphere of industrial production is hardly possible to be successful. That's why we should think about harmonisation when combining system engineering and project management. In the end, we have to develop the specialised national standard that includes both system engineering and project management. Second (especially important for Russia), the large number of enterprises have the basic level of their competence in project management. Due to that fact, the use of such comprehensive and costly tools like IPMA Delta ${ }^{\circledR}$ and other professional certification systems for organisations are not efficient at this time. The Ministry considers the necessity for creation of VCS for all enterprises in all industries.

Taking into account these two factors, the general requirements for the VCS are as follows:

- it should cover aspects of system engineering and project management;

- it should involve all significant enterprises of the industry;

- the cost of certification should not be burdensome either for enterprises or for the state;

- certification should not require the involvement of a large number of highly professional and expensive experts.

These requirements are reflected in the key provisions of the concept of the voluntary certification system for industrial enterprises.

\section{B. Competence model}

The term "competence" applies to the organisation. It means the ability of the organisation to achieve its goals thoughtfully combining and applying the competencies of available individual employees, strategic, structural and cultural competencies, and efficiently using the assets at disposal in the implementation of projects, programmes and portfolios.

The competence model covers three areas - Project Governance, Project Management and System Engineering. Each area contains the defined five sections (criteria), covering all aspects of project activity significant for enterprises in this or that industry.

The area of Project Governance includes the setting of goals and the establishment of policies (fundamental principles and rules), under which the project activities of the organisation are directed and controlled. The objects of evaluation (criteria) in this competency area are:

- $\quad$ strategic project management;

- organisational support for project activities;

- $\quad$ personnel and project management culture of the enterprise;

- $\quad$ corporate standard of project management; 
- corporate project management information system.

The area of Project Management includes the definition of methods, tools, techniques and competencies used by project management personnel. This area includes the topics (criteria) that are most critical in terms of efficiency of all projects:

- $\quad$ project scope management;

- $\quad$ project time management;

- $\quad$ project cost management;

- the project team and stakeholder management;

- $\quad$ project risk management.

The area of System Engineering focuses on the application of aspects, typical for project management of industrial complex and complicated products, systems, facilities. These criteria include:

- the complex object lifecycle management;

- requirements management;

- configuration management of products and projects;

- computer-aided engineering;

- industrial cooperation management.

Each criterion contains 6 sub-criteria in the form of questions for the assessment purposes. Thus, the overall structure of the competency model includes 90 sub-criteria questions.

As shown in the Fig.3, the set of competence elements covers all areas of competence defined by the IPMA OCB [4]. Competence classes defined in the model are fully corresponding to the first three classes of the IPMA Delta ${ }^{\circledR}$ Model - Initial, Defined and Standardised. This approach and model structure will greatly help the candidate organisations to prepare for the international assessment and certification

\section{Evaluation techniques}

The evaluation process is based on the IPMA Delta ${ }^{\circledR}$ model and includes three main steps:

- $\quad$ self-assessment of the organisation;

- verifying and refining preliminary conclusions during assessors' site visit to the organisation;

- final evaluation and recommendation development by assessors.

The self-assessment is performed using specialised questionnaire, covering all criteria of the model described in the article above.

The questionnaire contains 90 questions according to the Likert Scale. The questions are constructed in terms of "positive judgments", each of which the Respondent evaluates on a 5-point scale:

- 5: Yes ("Strongly agree");

- 4: Likely Yes ("Agree");

- 3: Neutral ("Neither Agree nor Disagree");

- 2: Likely No ("Disagree");

- 1: No ("Totally Disagree").

As an example, consider a section of project scheduling and control (Table. I). This section includes six statements describing the management process of scheduling and control. For each statement, the Respondent is asked to evaluate it using the Likert scale.

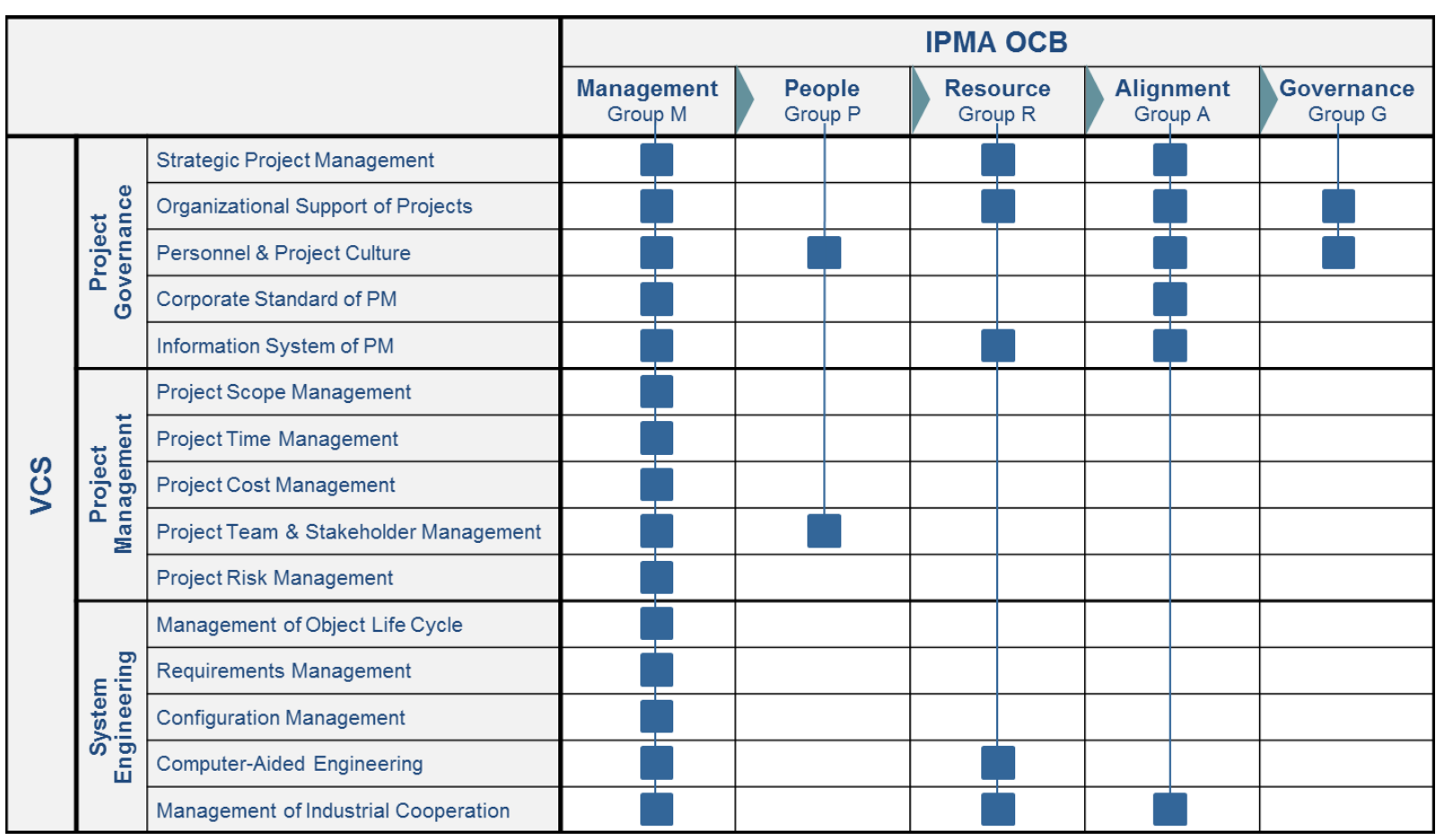

Fig. 3. Correspondence of the elements of project competence of industrial enterprises model and IPMA OCB 
TABLE.I. FRAGMENT OF QUESTIONNAIRE SELF-TEST

\begin{tabular}{|l|l|l|l|l|l|}
\hline \multirow{2}{*}{$\begin{array}{l}\text { Project scheduling and } \\
\text { control }\end{array}$} & \multicolumn{3}{|c|}{ Is it true for Your organisation? } \\
\cline { 2 - 5 } & Yes & $\begin{array}{c}\text { Likely } \\
\text { Yes }\end{array}$ & Neutral & $\begin{array}{c}\text { Likely } \\
\text { No }\end{array}$ & No \\
\hline $\begin{array}{l}\text { 1. Key milestones of the } \\
\text { project are defined for the } \\
\text { entire project life cycle }\end{array}$ & & & & & \\
\hline $\begin{array}{l}\text { 2. Duration of activities is } \\
\text { determined, taking into } \\
\text { account their complexity } \\
\text { and the resources allocated }\end{array}$ & & & & & \\
\hline $\begin{array}{l}\text { 3.Templates previously } \\
\text { created on the basis of } \\
\text { experience of similar } \\
\text { projects are used for } \\
\text { scheduling }\end{array}$ & & & & & \\
\hline $\begin{array}{l}\text { 4. A project schedule is } \\
\text { optimised using the of } \\
\text { critical path methods, } \\
\text { critical chain method, or } \\
\text { other methods }\end{array}$ & & & & & \\
\hline $\begin{array}{l}\text { 5. The validity of the } \\
\text { schedule is discussed and } \\
\text { confirmed by good } \\
\text { practices }\end{array}$ & & & & & \\
\hline $\begin{array}{l}\text { 6. Management receives } \\
\text { timely, relevant and } \\
\text { accurate information on the } \\
\text { progress of the project }\end{array}$ & & & & & \\
\hline
\end{tabular}

To provide the self-assessment objectively, a large number of managers and specialists of the company should be involved in the self-assessment process. It is recommended to involve the following individuals:

- top-managers or steering board members governing project-oriented activities;

- functional managers governing projects, programs, portfolios;

- project managers of all types of projects;

- line personnel involved in project activities.

For statistical reasons, it is recommended to have a sample of at least 30-35 people. Due to the fact that some of the filled-in questionnaires may be rejected, the sample of more than 50 people is recommended. Test reliability-consistency of results of the survey carried out by the method of Cronbach's $\alpha$ (alpha) coefficient.

The following rules should be applied at a preliminary competency class definition:

1) For each questionnaire, item class competence is determined on the basis of the evaluation given in relation to item $(E)$ by the following rules:

- first-class of competence: $1.5 \leq E<2.5$;

- $\quad$ second class of competence: $2.5 \leq E<3.5$;

- the third class of competence: $E \geq 3.5$.
2) For each section of the questionnaire, the class of competence for this section $\left(N_{I}\right)$ is determined according to the following rules:

- at least four paragraphs in this section have the class $N_{l}$ and more;

- no one has a class of $N_{I}-2$.

3) For each area of the questionnaire, class competence in this area $\left(N_{2}\right)$ is determined according to the following rules:

- at least three sections of this area have a class $N_{2}$ and more;

- $\quad$ neither section has no class $N_{2}-2$.

4) Final class competence of an organisation is defined as the minimum grade in all three competency areas.

Preliminary evaluation of the competence class, obtained as the result of the survey, is verified and refined by the analysis of documentation and the interviews with the respondents during the site visit of assessors. The recommendations are developed by the assessors after the final evaluation.

The VCS for the enterprises is registered by the Federal Agency for Technical Regulation and Metrology (May 12, 2017)

\section{Maturity Model Of The Project MANAGEMENT SYSTEM}

\section{A. Vision and approach}

Project management is a relatively new practice even for federal executive bodies. For most regions, the history of project management implementation is limited to 1-2 years. In general, they are guided by federal regulatory documents $[5,6]$, but each region is looking for its own developmental path.

The Ministry is interested in the harmonization of its own approaches, and the regional practices since a large number of projects are implemented with the joint participation of federal and regional authorities.

In addition, the Ministry is interested in making sensible ideas and good practices formed in any regions available to other regions, in aligning the culture of project management in the regional industrial departments.

These goals determine the structure of the maturity model, which includes four areas of assessment - project activity organization, strategic management, project management and project management culture.

The organization of the project activities is of high priority in the regional governments. That is why in the overall assessment of the maturity, these issues received the greatest weight - $35 \%$ of the maximum score. This area includes:

- creating the necessary regulations for project activities; 
- $\quad$ establishing and functioning of permanent PMOs as operational bodies for projectoriented activities, including the project management office of industrial department;

- creating and functioning of the regional communities in key areas of industrial development.

The next most important area is strategic management (30\% of the maximum score). In this area, the processes of ranking and selection of projects, the compliance of the formed portfolios with the regional industry development strategy and its target indicators are assessed.

The project management area $(25 \%$ of the maximum score) includes the traditional processes of initiating, planning, monitoring, and completing the projects. These processes should fully reflect the needs of the executive authority as an investor or project regulator. The model pays special attention to change management issues.

The area of project management culture includes the development and improvement of project activities. Training and certification are the main focus of attention here. In addition, the processes of gathering and dissemination of best practices are of fundamental importance for the Ministry. The weight of this area in the overall assessment of maturity is still relatively small $-10 \%$. However, in the near future, the task of raising the project management culture will come to the foreground.

\section{B. Case study}

Approbation of the maturity model was carried out within the framework of the "Project Olympus" contest. The team of assessors included experienced certified project management specialists and representatives of the Ministry. Eight reports were submitted to the contest; four regions were admitted to the second round. In each of these regions, a site visit of assessors was conducted.

Analysis of the assessment results showed a generally low level of maturity. Even the winner of the contest scored less than $50 \%$ of the possible points. At the same time, a rather high score was obtained in the area of organization of project activities and, expectedly low, by the project management culture (Fig 4).

Regulatory support and Strategic planning turned out to be the greatest strengths of the system $(81 \%$ and $70 \%$ of maximum, respectively). Rapid progress in these areas could be easily explained - this is the usual way of working for officials. The weakest sides were Change management and Project closing (18\% of maximum both). This could be explained by the fact that the activities implemented in the project management approach have not yet entered the phase when these processes become normal practice.

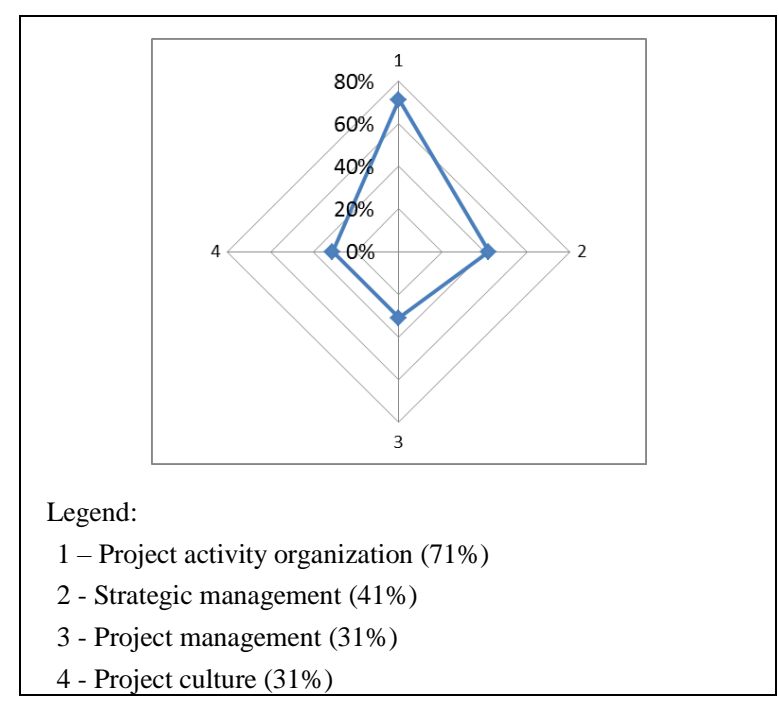

Fig. 4. Evaluations by areas (per cent of maximum)

The assessment revealed several practices that the Ministry recommended for implementation at the regional level. Especially important are ideas related to the development of the project management culture. For example, the three-year cycle of planning of individual professional development of employees was included in project activities.

\section{CONCLUSION}

The approaches considered in the paper are an integrated system for assessing the level of competence of project management activities in the industry. It covers all the significant groups of subjects of project management activities and establishes the requirements for each of these groups.

These models and metrics correspond to the current state of project activities and, of course, should and will be developed.

However, it is important to mention that the evaluation is not the final goal for the Ministry. Other areas of project management such as the development of standards, training the managers and line personnel, implementation of information systems, creating the professional community are also progressing in parallel and in close relationship with each other.

Thereby, implementation of the evaluating systems is important, but not the only step towards the creation of a wide expert and professional community of project management specialists in the industry.

The main tasks of the community should be:

- identification and dissemination of industry good practices;

- the expertise of methods and tools of project management;

- development of recommendations for their implementation in the industry;

- development of industry standards for project management; 
- preparing proposals for changes in legislation to improve project management activity in the industry.

Further ideas for the development of project management in the industry are shared and supported at the level of top management of the Ministry.

\section{REFERENCES}

[1] G. Nicitin, A. Barykin, V. Slyshkin, and G. Tsipes, "Engineering, and Infrastructure Projects in Ministry of Industry and Trade of Russia: Balance of Governance and Management", Procedia Social and Behavioral Sciences, Volume 226, 14 July 2016, pp. 358-364

[2] IPMA Delta (2015), "IPMA Delta - moving organizations forward in translating strategy into results", available at
https://www.ipma.world/assets/IPMA_Delta_Brochure_ENG _2015_Screen.pdf (accessed 24 July 2018)

[3] V. Osmakov, A. Uchenov, A. Tovb, and G. Tsipes. "Projectoriented management in the Ministry of industry and trade of the of Russian Federation: Experience of analysis", in Project Management and its Impact on Societies, 6th Research IPMA Conference, Rio de Janeiro, Brazil, Sept 3-4, 2018, pp. 140163.

[4] IPMA OCB, Organisational Competence Baseline for Developing Competence in Managing by Projects. Version 1.1 - IPMA, 2013, $157 \mathrm{p}$.

[5] Regulations on the organization of project activities in the Government of the Russian Federation, approved by the Government of the Russian Federation of October 31, 2018 No. 1288

[6] Guidelines for the organization of project activities in federal executive bodies, approved by the Government Office of the Russian Federation dated March 12, 2018, No. 1937, p-P6. 